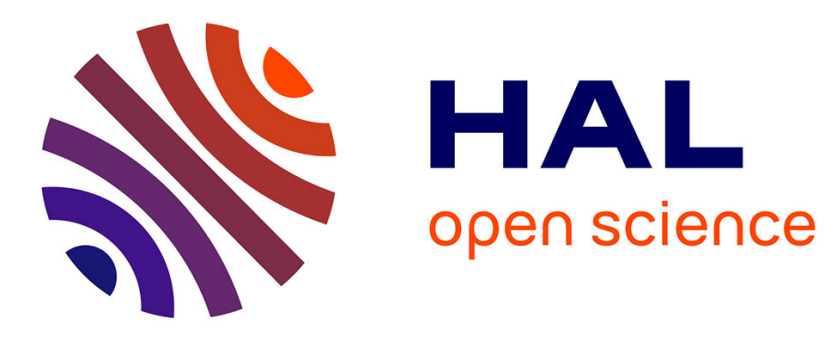

\title{
Cultural Domains and Class Structure: Assessing Homologies and Cultural Legitimacy
}

\author{
Nicolas Robette, Olivier Roueff
}

\section{To cite this version:}

Nicolas Robette, Olivier Roueff. Cultural Domains and Class Structure: Assessing Homologies and Cultural Legitimacy. Jörg Blasius; Frédéric Lebaron; Brigitte Le Roux; Andreas Schmitz. Empirical Investigations of Social Space, Springer, pp.115-134, 2019, 10.1007/978-3-030-15387-8_8 . halshs02437239

\section{HAL Id: halshs-02437239 \\ https://shs.hal.science/halshs-02437239}

Submitted on 13 Jan 2020

HAL is a multi-disciplinary open access archive for the deposit and dissemination of scientific research documents, whether they are published or not. The documents may come from teaching and research institutions in France or abroad, or from public or private research centers.
L'archive ouverte pluridisciplinaire HAL, est destinée au dépôt et à la diffusion de documents scientifiques de niveau recherche, publiés ou non, émanant des établissements d'enseignement et de recherche français ou étrangers, des laboratoires publics ou privés. 


\section{Metadata of the chapter that will be visualized online}

\begin{tabular}{|c|c|c|}
\hline Chapter Title & \multicolumn{2}{|c|}{$\begin{array}{l}\text { Cultural Domains and Class Structure: Assessing Homologies and } \\
\text { Cultural Legitimacy }\end{array}$} \\
\hline Copyright Year & \multicolumn{2}{|l|}{2019} \\
\hline Copyright Holder & \multicolumn{2}{|c|}{ Springer Nature Switzerland AG } \\
\hline \multirow[t]{7}{*}{ Corresponding Author } & Family Name & Robette \\
\hline & Particle & \\
\hline & Given Name & Nicolas \\
\hline & Suffix & \\
\hline & Organization & ENSAE \\
\hline & Address & Palaiseau, France \\
\hline & Email & nicolas.robette@uvsq.fr \\
\hline \multirow[t]{7}{*}{ Author } & Family Name & Roueff \\
\hline & Particle & \\
\hline & Given Name & Olivier \\
\hline & \multicolumn{2}{|l|}{ Suffix } \\
\hline & Organization & $\begin{array}{l}\text { Centre de recherches sociologiques et } \\
\text { politiques de Paris - CRESPA }\end{array}$ \\
\hline & Address & Paris Cedex 17, France \\
\hline & Email & o.roueff@free.fr \\
\hline
\end{tabular}

Abstract

It is well known that the figures representing the French social space in Distinction (Bourdieu 1979) are based on several partial analyses. This means that one of Pierre Bourdieu's central hypotheses - the structural homology between social and cultural spaces as wholes - was not empirically tested by way of correspondence analysis (although Bourdieu did perform such an analysis for the bourgeoisie and petite bourgeoisie). Furthermore, many of the sociological discussions of cultural practices which have appeared since the publishing of Distinction use data describing a single taste domain, often music. This is beginning to change, as large-scale surveys have been conducted for Australia (Bennett et al. 1999), Norway (Rosenlund 2000), Porto in Portugal (Borges Pereira 2005), Aalborg in Denmark (Prieur et al. 2008), Great Britain (Bennett et al. 2009) - but not for France. Furthermore, as it has never been empirically tested, it is not obvious that cultural tastes constitute a homogeneous universe of practices. They can be structured by domains, depending on the relative autonomy of their respective fields of production: taste in music is not necessarily distributed in the same way as taste in books, and their relation to the social space may also differ. The French survey on cultural practices Pratiques culturelles des Français (PCF 2008), enables new implementations and tests of these hypotheses through empirical analysis. 


\title{
Chapter 8
}

\section{Cultural Domains and Class Structure:}

Legitimacy

\author{
Nicolas Robette and Olivier Roueff
}

\section{Introduction}

It is well known that the figures representing the French social space in Distinction 7 (Bourdieu 1979) are based on several partial analyses. This means that one of Pierre 8 Bourdieu's central hypotheses - the structural homology between social and cultural 9 spaces as wholes - was not empirically tested by way of correspondence analysis 10 (although Bourdieu did perform such an analysis for the bourgeoisie and petite 11 bourgeoisie). Furthermore, many of the sociological discussions of cultural practices 12 which have appeared since the publishing of Distinction use data describing a single 13 taste domain, often music. This is beginning to change, as large-scale surveys have 14 been conducted for Australia (Bennett et al. 1999), Norway (Rosenlund 2000), Porto 15 in Portugal (Borges Pereira 2005), Aalborg in Denmark (Prieur et al. 2008), Great 16 Britain (Bennett et al. 2009) - but not for France. Furthermore, as it has never been 17 empirically tested, it is not obvious that cultural tastes constitute a homogeneous 18 universe of practices. They can be structured by domains, depending on the relative 19 autonomy of their respective fields of production: taste in music is not necessarily 20 distributed in the same way as taste in books, and their relation to the social space 21 may also differ. The French survey on cultural practices Pratiques culturelles des 22 Français (PCF 2008) ${ }^{1}$, enables new implementations and tests of these hypotheses 23 through empirical analysis.

${ }^{1}$ See all details here: http://www.pratiquesculturelles.culture.gouv.fr/doc/08methodologie.pdf

N. Robette $(\triangle)$

ENSAE, Palaiseau, France

AQ2

e-mail: nicolas.robette@uvsq.fr

O. Roueff

Centre de recherches sociologiques et politiques de Paris - CRESPA, Paris Cedex 17, France

(C) Springer Nature Switzerland AG 2019

J. Blasius et al. (eds.), Empirical Investigation of the Social Space,

Methodos Series 15, https://doi.org/10.1007/978-3-030-15387-8_8 
We first tested empirically the hypothesis of a homology between different 25 domains of the most detailed tastes in the dataset - TV, reading, cinema and music. 26 Multiple correspondence analysis (MCA) allows us to compare the four tastes' 27 spaces, while multiple factor analysis (MFA) is employed as a method to test their 28 homology.

Further analyses deal with the homology between these tastes' spaces and the 30 whole space of social positions. Indeed, quantitative works often conclude that the 31 cultural practices that are most associated with social class are also distributed by 32 age and by sex (Coulangeon 2003; Bennett et al. 2009; Détrez 2011; Octobre 2011; 33 Christin 2012; Roose et al. 2012). The assumption is sometimes made that, today, 34 the distribution of tastes is structured equally by age and sex and by social class 35 (Bennett et al. 2009), and even that we can observe the weakening of cultural 36 class divisions in favour of generational cultural divisions (Glévarec and Pinet 37 2017). In order to shed some light on this question, we untangled the web of 38 factors - e.g. education, gender and age - structuring lifestyles in France by using 39 several geometric data analysis techniques (Le Roux and Rouanet 2004), including 40 standardized factor analysis (Bry et al. 2015). The research questions we intend 41 to answer include: has age supplanted class membership in importance? If this is 42 the case, should it be interpreted in terms of each individual's actual age, or with 43 regard to their membership of a generational group? Has the opposition between 44 economic and cultural capital lost its relevance? And is the axis ordering volumes 45 of capital a good proxy for the scale of cultural legitimacy, as is usually postulated 46 by sociologists?

Finally, after exploring these issues at the scale of the whole social space, we 48 ask whether the results apply to a smaller scale by 'zooming' in on different social 49 classes using class specific analysis (CSA). Does the level of heterogeneity in social 50 classes' tastes increase at the higher levels of the social space, due to a broader range 51 of practices among the upper classes (Peterson and Kern 1996)? Does the opposition 52 between legitimate and popular culture organise the symbolic antagonism between 53 classes from opposite ends of the social space? If so, is it invariably the same tastes 54 that transmit this opposition?

The present chapter offers a set of results, albeit without going into great 56 detail. Our goal is merely to present a sociological approach comprising statistical 57 tools taken from the geometrical data analysis family, and sometimes elsewhere. 58 Statistical algorithms are chosen (or created) to answer a sociological question 59 depending on what exactly they $d o$ with data. First, each question demands an 60 exploration of the tools to be chosen or created; the best tools are rarely the most 61 obvious, and the answer will not be preordained (a MCA for representing a social 62 space, a hierarchical clustering analysis for quickly obtaining a typology, and so on). 63 Second, most questions are better dealt with if several tools are used, as each tool 64 offers a very specific and narrow view on data, and rarely corresponds exactly to the 65 sociological question. Statistical tools - whether geometrical or inferential - only 66 describe data by reducing and organising information (as do algorithms) in multiple 67 ways, and offer only partial clues (and only sometimes convincing ones) to help 68 develop a sociological explanation of the statistical observations. 
The fact that cultural tastes constitute a homogeneous universe of practices cannot 71 be taken for granted. They are structured by cultural domains, depending on the 72 relative autonomy of fields of production specialised in a particular type of symbolic 73 good. Tastes in music are not necessarily organised in the same way as tastes 74 in television, since the field of music operates in a quite different way from the 75 field of television, and the social uses of music are different from the social uses 76 of television. Thus the hypothesis of a structural homology between each of the 77 fields in question, which would represent the main statistical proof of the relative 78 homogeneity of consumption habitus, should be tested empirically. 79

Several methods are possible. The first is to perform four separate Multiple 80 Correspondence Analyses (MCA) - that is to say, one for each domain of practices - 81 and to compare their structuring factors and the distribution of categories. This 82 method has the advantage of respecting the specific structuring principles in every 83 domain: it accounts for these principles with no interference from the other domains. 84 But it is really only appropriate for an initial investigation: the four domains are 85 roughly similar. It is difficult to go beyond a superficial comparison - with the naked 86 eye, so to speak - of the four series of plots (of individuals and/or categories) and 87 any potential aids to interpretation; the coordinates of the taste variables and the 88 correlations between the variables which determine social position are not strictly 89 comparable from one domain to another, as they are produced by distinct processes 90 of MCA.

The second method is to perform a single MCA combining the four groups of 92 variables. This has the advantage of allowing a direct comparison: the categories 93 are scattered on the same plot, and aids to interpretation rank the variables and 94 categories of the four domains all together. However, there is no assurance that the 95 domains will contribute to the results of the MCA in a balanced way. A domain 96 can have more weight, dominating others - for example due to a greater number of 97 variables - which is not justified from an analytical point of view: we want instead 98 for all domains to contribute equally to the construction of the space of tastes. 99

We turn therefore to a third method, multiple factor analysis (MFA), which was 100 developed by Brigitte Escoffier and Jerome Pagès in the 1980s (Escofier and Pagès 101 1990, 2008; see also Baier \& Schmitz in this volume). It fruitfully combines the 102 benefits of the previous two approaches: from the same data set, it balances the 103 contributions of several groups of variables (here the four domains of taste) to the 104 construction of the space. In this way it accounts for the correlations within each 105 domain and between whole domains, whereas MCA does not allow us to weigh 106 up the influence of each group of variables; this is thus a way to superimpose the 107 four spaces of tastes over one another. Technically, MFA involves performing a 108 separate MCA for each domain, combining individuals' coordinates on the axes of 109 the MCA, resulting in a principal component analysis (PCA) from these coordinates 110 weighted by the variance of the first axis of the domain. We can then switch between 111 


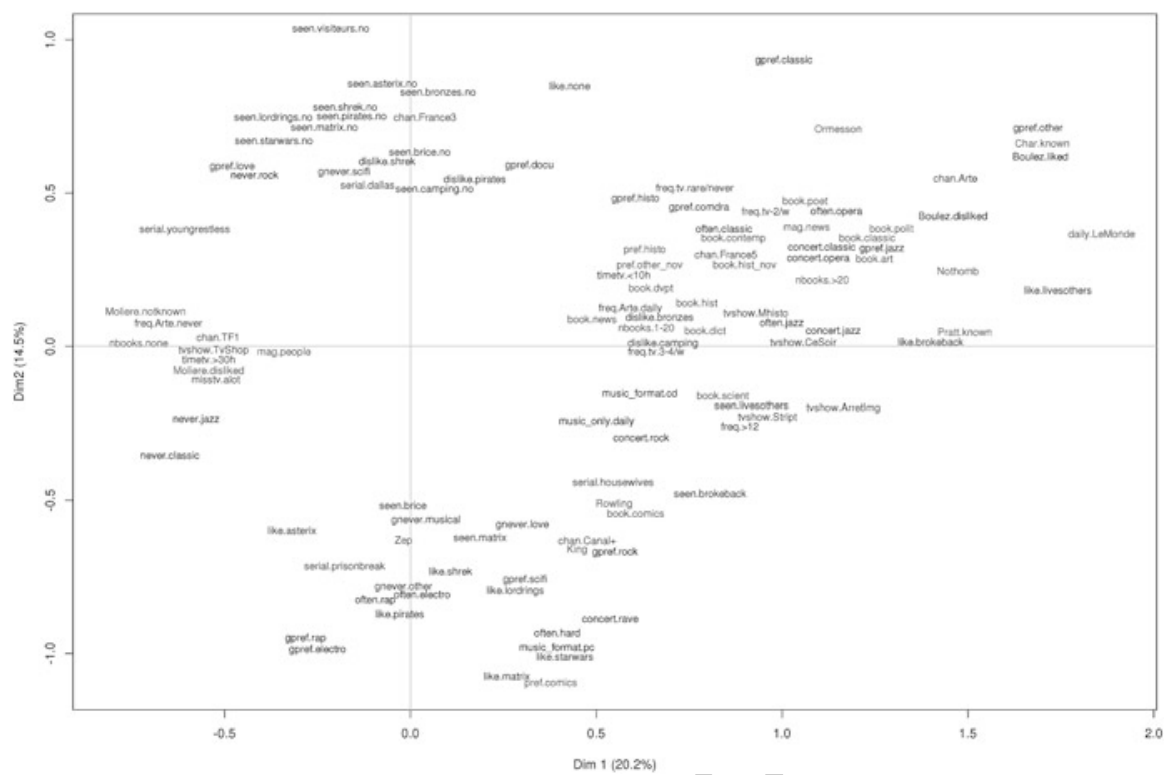

Fig. 8.1 MFA of the tastes in music, cinema, television, and reading

observing each isolated space (by 'deleting' the others) and the global space of the 112 four domains all together (Fig. 8.1).

It is worth mentioning that all the correspondence analyses performed here are 114 'specific'. This will set some categories of variables as 'passive' so that they do not 115 contribute to the construction of the space, especially in the case of 'junk' categories 116 such as 'other' or 'not specified', or categories with low frequencies; these might 117 weigh artificially on the construction of the space (Le Roux and Rouanet 2004). 118 We used R software and the GDAtools package, which has all the geometric data 119 analysis tools used here (MFA, specific MCA, CSA, ellipses, and so on. http://cran. 120 r-project.org/web/packages/GDAtools/index.html).

The comparison of the four 'universes' of tastes constructed by the MFA 122 confirms the overall homology between the four spaces (Robette and Roueff 2017). 123 This comparison relies less on the plots than on the selection of the most significant 124 categories (by axis and by domain). For a given axis, the categories are considered 125 'notable' if their coordinates are greater than 0.5 or less than -0.5 , meaning that the 126 category is at a remove of at least 0.5 relative to 0 : this is a "rule of thumb" suggested 127 by Le Roux and Rouanet (2010: 59) for categories projected as supplementary. Due 128 to the two-stage process of the MFA (separate MCAs and then PCA), taste variables 129 are considered as supplementary from a statistical point of view (even if they remain 130 active from an interpretive point of view), hence the use of this rule of thumb rather 131 than of the contributions to axes (valid with active variables only). Bolded categories 132 are those whose coordinates on the axis are greater than 1 or less than -1 : we ${ }_{133}$ consider these categories 'highly notable'. 
Table 8.1 Notable (and highly notable) categories for axis 1, by domain

\begin{tabular}{l|l|l}
\hline Axis 1 & Left & Right \\
\hline Reading & $\begin{array}{l}\text { Nb books read = none, } \\
\text { don't know Molière, don't } \\
\text { like Molière, read people } \\
\text { magazines }\end{array}$ & $\begin{array}{l}\text { Read Le Monde, know Char, read Pratt, read } \\
\text { Nothomb, read politics, art and classic books, } \\
\text { ever read d'Ormesson, nb books read > 20, read } \\
\text { news magazines, read poetry, read historical, } \\
\text { contemporary, science or history books, } \\
\text { dictionaries, self-help books, other genres of } \\
\text { novels, nb books read 11-20, prefer history books, } \\
\text { ever read Rowling, read news books }\end{array}$ \\
\hline Cinema & - & $\begin{array}{l}\text { Like The Lives of Others, preferred genre = } \\
\text { other, like Brokeback Mountain, have seen The } \\
\text { Lives of Others, more than 12 times a year, have } \\
\text { seen Brokeback Mountain, comedy-drama, dislike } \\
\text { Camping, dislike Les Bronzés, like historical } \\
\text { movies }\end{array}$
\end{tabular}

Axis 1 combines, for the four domains, categories of intensity of practice (high on 135 the right side, low on the left side) and categories of taste that can be interpreted as 136 bourgeois (to the right) or popular (to the left). This is confirmed by the projection 137 of individual social characteristics as supplementary variables. The respondent's 138 own educational level "explains" $31 \%$ of the variance of axis 1, their PCS (i.e. the 139 French profession et catégorie socioprofessionnelle) 29\%, the mother's educational 140 level $16 \%$ and the PCS of the head of household 16\%. Age explains 28\% of the 141 variance of axis 2 , and gender $9 \%$.

For the four domains, the most notable categories are often ones that denote 143 singular works rather than cultural genres (Table 8.1) - which is probably due to 144 their rarity, but is also an indication of the strength of the interpretation (Robette 145 and Roueff 2014). They are also all grouped on the right, suggesting legitimate, 146 bourgeois tastes, while the left side exhibits far fewer notable categories. Thus, the 147 axis objectivizes proximity vs remoteness to culture in general, and to bourgeois 148 culture in particular - on the left, the only notable positive categories are TF1 (the 149 main commercial TV channel), the soap opera Les Feux de l'Amour (The Young and 150 the Restless), teleshopping programmes and gossip magazines. 151

As for axis 2, it is not related to intensity of practice (Table 8.2), with the 152 exception of the category never or seldom television. On the other hand, it is notably 153 associated with taste categories, especially for singular works. The four domains 154 
Table 8.2 Notable (and highly notable) categories for axis 2, by domain

\begin{tabular}{|c|c|c|}
\hline Axis 2 & Bottom & Top \\
\hline Reading & $\begin{array}{l}\text { Preferred genre }=\text { comics, ever read } \\
\text { Stephen King, Zep, read comics, ever } \\
\text { read Rowling }\end{array}$ & Like d'Ormesson, know Char \\
\hline Cinema & $\begin{array}{l}\text { Like Matrix, like Star Wars, like } \\
\text { Pirates of the Caribbean, gjms autre, } \\
\text { like The Lord of the Rings, preferred } \\
\text { genre = science-fiction, like Shrek, } \\
\text { have seen Matrix, have seen Astérix et } \\
\text { Obélix, never watch romance or } \\
\text { musical movies, have seen Brice de } \\
\text { Nice }\end{array}$ & $\begin{array}{l}\text { Haven't seen Les Visiteurs, aime aucun, } \\
\text { haven't seen Astérix et Obélix / Les Bronzés } \\
\text { / Shrek / Pirates of the Caribbean / Matrix / } \\
\text { The Lord of the Rings, preferred genre = } \\
\text { other, haven't seen Star Wars / Brice de } \\
\text { Nice, dislike Shrek, preferred genre = } \\
\text { documentaries, preferred genre = romance, } \\
\text { never watch science-fiction, dislike Pirates } \\
\text { of the Caribbean, haven't seen Camping, } \\
\text { preferred genre = historical movies }\end{array}$ \\
\hline Music & $\begin{array}{l}\text { Computer format, preferred genre }= \\
\text { electronic or hip hop, often listen to } \\
\text { heavy metal, rave parties, often listen } \\
\text { to hip hop or electronic, preferred } \\
\text { genre = rock }\end{array}$ & $\begin{array}{l}\text { Preferred genre = classical, like Boulez, } \\
\text { never listen to rock }\end{array}$ \\
\hline Television & Prison Break, Canal+ & France 3, Arte, Dallas, rarely/never \\
\hline
\end{tabular}

exhibit similar overall profiles: at the bottom of the Figure are emerging (new) tastes, 155 at the top are established (old) tastes. 156

The advantage of MFA is not only its ability to confirm the homology between 157 the four domains, but also that it allows us to study any potential small variations. 158 Indeed, this approach ensures that these variations do not result from an imbalance 159 of contributions of each domain, as they were standardized on the first axis: the 160 comparison is based on a statistical foundation. 161

Thus, for axis 1, the differences between domains concern the presence, for 162 movies only, of two categories of distaste on the left side (distaste for the lowbrow 163 comedies Camping and Les Bronzés font du ski), the presence, for TV and reading 164 only, of positive categories on the right side, and above all the absence of categories 165 on the right side for movies only. Distaste for the music of the composer Pierre 166 Boulez, on the left side, can be interpreted differently: this category is very close to 167 the one of taste for Boulez, so it is the fact of knowing Boulez and thus being able to 168 express a taste or distaste for his music which is distinctive. The same phenomenon 169 is observed by Duval (2011) and Savage and Gayo (2011). For the category cinema, 170 all movies' categories on the right side have coordinates lower than 0.5: individuals 171 who are distant from bourgeois culture are more likely to express a taste for romance 172 or action movies, Titanic or Les Bronzés font $d u$ ski; however, these categories are 173 not notable, probably because they are common, in contrast to more distinctive 174 expressions of tastes such as not reading books; disliking jazz; never watching Arte 175 (the main cultural TV channel) but often TF1 (the main commercial TV channel); 176 or enjoying gossip magazines or Les Feux de l'Amour (The Young and the Restless), 177 where the distances are all much greater. Cultural tastes that stray from the bourgeois 178 
legitimacy are more likely to be weakly held; cultural tastes which can be classified 179 as 'legitimate' are also more likely to be strongly held.

For axis 2, the differences between domains are visible only in the predominance 181 of the categories taste in movies. Notable here is the presence of many categories 182 of no activity, particularly at the top of the axis: the fact of not having seen these 183 films can be thought of as a form of classifying, even if we cannot consider these 184 categories as expressions of distaste. However, axis 2 is not a replica of the axis 1185 opposition between bourgeois and popular tastes. Television tastes at the bottom 186 are not necessarily those with the largest audience, but are popular with young 187 respondents. One can even determine details such as the fact that the commercial 188 channel Canal+ and the American serial drama Prison Break are favoured in 189 particular by relatively young graduates. Conversely, the established series Dallas 190 is at the top of the space. Among other emerging tastes appear comics in the reading 191 category, and for the genres electro, rap, hard and rock for music (while tastes for 192 international varieties and French varieties are specifically popular, at the right of 193 axis 1, and not distinctive on axis 2). Finally, movie tastes at the top of the axis can 194 mostly be characterised by their remoteness to the movies and genres to be found at 195 the bottom (action movies, science fiction, comedy); those at the top include the taste 196 for documentary and historical films, but also for romance movies. It is especially 197 evident in the cinema category that axis 2 opposes simultaneously emerging to 198 established tastes, as well as male to female tastes. A gendered pattern of opposition 199 can be established, for example, regarding a lack of interest in romance or musicals 200 and a lack of interest in science fiction. Similarly, when one lowers the threshold 201 for notability with this interpretation in mind, other gendered categories can also 202 be found in the categories reading and television: the female taste for reading the 203 romantic Harlequin paperback series vs. the male taste for the celebrity talkshow 204 La méthode Cauet, for example.

\section{The Homology Between Social Space and the Space of Tastes}

\section{The Homology Between Class Tastes}

A level of structural homology has been established for tastes. What about social 208 properties? We will not examine in detail here the homology between the space of 209 tastes and the social space as a whole - instead, we will return to this overarching 210 theme later, refining the basic verification of the presence of homology by adding 211 supplementary variables correlated to the first two axes. We are first interested in 212 the spaces of social classes: are the cultural universes of the bourgeois, intermediate 213 and popular classes structured by the same principles? It may be the case that 214 correspondence analyses, which give more weight to rare categories (thus, here, 215 to the bourgeois classes), combined with a relatively 'legitimistic' questionnaire 216 specifically detailing the practices which the dominant perspective defines as 217 
cultural, lead to a space entirely defined by the properties of the bourgeois classes. 218 We intend to show that this is not the case, or rather that the undeniable bias 219 produced by the questionnaire and the technique must be interpreted differently. 220 On the one hand, it is essentially the distance to legitimate culture that is being 221 measured, even if one does not measure that exclusively. We will point out some 222 clues of the relative autonomy of popular tastes, organised according to other logics 223 than merely their relation to legitimate or intellectual culture (Grignon and Passeron 224 1989; Fabiani 1995). On the other, however, it is possible by this very method to 225 observe how the distribution of cultural tastes are similar from one social class 226 to another, even for the popular classes: legitimate culture produces a scale of 227 legitimacy that organises, at least in part, the tastes of all social classes, including 228 those social groups which are the most remote from the bourgeois centre of the 229 production of legitimacy. The benefit of such an analysis is therefore again to 230 observe both the overall replication of the same structure and local variations within 231 the overall structure.

In conducting such a comparison, the difficulty is similar to that encountered 233 in the case of homologies between cultural domains: how can we avoid both the 234 separate construction of specific spaces for each class - which would thus be statis- 235 tically incommensurable - and the imbalance of respective weights of the classes? 236 With this in mind, as an initial approach we plot on the cloud of individuals of the 237 overall MFA the ellipses of concentration of the subpopulations corresponding to 238 each class (Fig. 8.2). For the convenience of this cursory review of results, social 239 classes are simply defined based on occupational categories (the French catégories 240 socio-professionelles (CSP), as defined by INSEE): the bourgeoisie category is 241 cadres (executives), meaning intellectual professions, and managers of companies 242 with more than ten employees; for intermediate groups, the category is profession 243 intermédiaires (middle employees), which includes craftsmen, and retail traders; the 244 category for the popular classes encompasses lower-level employees and labourers. 245

While the distribution of individuals on the axis 2 is relatively similar from one 246 class to another, the dispersion on axis 1 - which indicates both intensity of cultural 247 practices and proximity to legitimate culture - increases with the volume of capital. 248 This is unsurprising, but we must also consider that there is a non-insignificant 249 dispersion within the working classes themselves - and therein lies one of the 250 interesting facets of the ellipses. The popular classes are not only non-consumers 251 of bourgeois culture, with some class fractions exhibiting oppositions according 252 to their relationship to bourgeois culture - bourgeois culture really is the heart of 253 legitimacy, scaling taste in the overall social space even though it does not exhaust 254 all the dimensions. In other words, we observe here an index of the social authority 255 or the symbolic power of the bourgeoisie in cultural matters.

To go further, we turn to class specific analysis (CSA), because it helps to build 257 a space for a subpopulation taking into account the distribution of categories in 258 the subpopulation and in the total population (Le Roux and Rouanet 2004). It is 259 particularly important, when constructing the space of a social class, to bear in mind 260 the fact that this space does not exist in isolation, but is part of a broader space - that 261 is, defined in relation to the rest of the population. In our case, we construct the space 262 


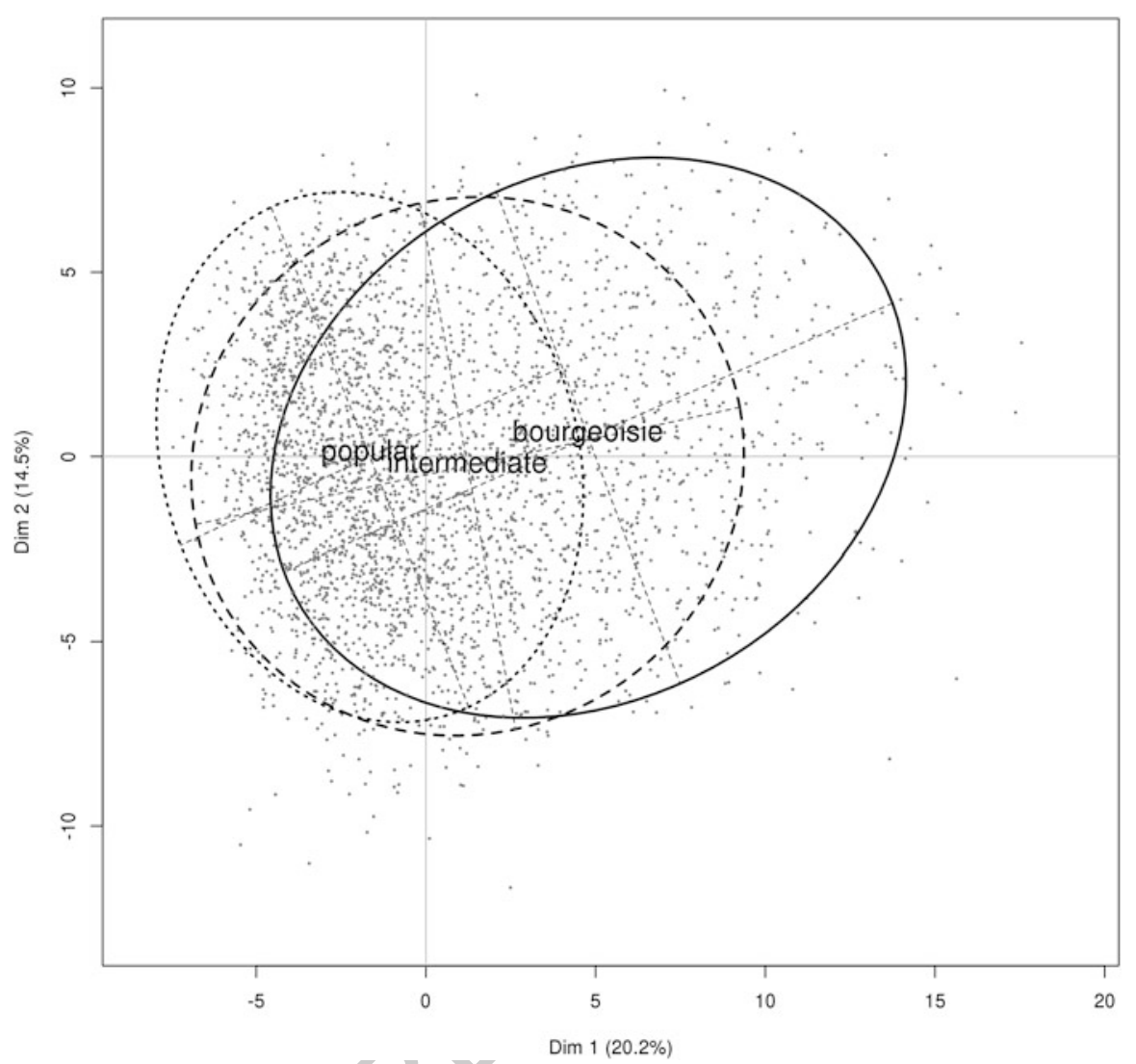

Fig. 8.2 Ellipses of concentration of social classes (on MFA cloud of individuals)

of tastes of active individuals in a given social class according to the space of the 263 entire population in the survey. We build the CSA from the global MFA, to continue 264 to compare the four domains of taste and the social classes simultaneously. We can 265 then study - in addition to the plots - the contributions to the axes of each domain 266 according to social class, the coordinates of the supplementary variables describing 267 social properties (such as degree or income, again according to social class), and 268 finally the categories which contribute the most to the axes, both by domain of taste 269 and social class. These data enable us to describe in detail each class's tastes, and 270 the way in which the different domains of tastes are structured for each social class. 271 However, their interpretation must be informed by both sets of previous results. For 272 lack of space, we only present the most interesting results.

First, we compare the contributions of the variables of each cultural domain to 274 the first two axes of the CSA of each social class, built from the global MFA (Table 275 8.3 ). 
Table 8.3 Contributions to social class specific MFA axes of the domains of tastes (\%)

\begin{tabular}{|c|c|c|c|c|c|c|}
\hline Classes & Axes & Music & Movies & Television & Reading & Total \\
\hline \multirow{2}{*}{ bourgeois } & 1 & 21,6 & $\mathbf{3 5 , 5}$ & 22 & 20,9 & 100 \\
\cline { 2 - 7 } & 2 & 14,3 & $\mathbf{5 4}$ & 26,1 & 5,6 & 100 \\
\hline \multirow{2}{*}{ intermediary } & 1 & $\mathbf{2 7 , 7}$ & 23,8 & 18,3 & $\mathbf{3 0 , 2}$ & 100 \\
\cline { 2 - 7 } & 2 & 16,7 & $\mathbf{6 9 , 4}$ & 7,2 & 6,7 & 100 \\
\hline \multirow{2}{*}{ popular } & 1 & 28,7 & $\mathbf{3 6 , 6}$ & 11,8 & 22,9 & 100 \\
\cline { 2 - 7 } & 2 & $\mathbf{4 2 , 1}$ & 15,8 & 15,7 & 26,4 & 100 \\
\hline
\end{tabular}

Reading: for popular classes, music contributes to $42,1 \%$ of the construction of axis 2

For the bourgeois classes, the contributions of the four domains are relatively 277 balanced on axis 1: internal differentiations in the bourgeois classes involve all cul- 278 tural tastes. The relative prominence of movies on both axes is, however, notable. It 279 is probably related to the distinguishing effect of even going to the cinema: the most 280 established part of the bourgeois classes distinguishes itself by its distance from the 281 cinema. Moreover, axis 1 is essentially correlated with cultural capital indicators 282 (table with eta ${ }^{2}$ available from authors): the interviewee's PCS summarizes $10 \%$ of 283 the variance, the mother's educational level $9.8 \%$, the interviewee's own educational 284 level $9 \%$, and the father's PCS $6.8 \%$. Income and assets are negligible. There is 285 also a slight effect of the distinction between public and private sector (3\% of the 286 variance), which is absent (or almost) in the other social classes: it may be the result 287 of the presence in this class of occupations dealing directly with information and 288 entertainment, and the scientific and teaching professions (except for primary and 289 secondary education). The second axis, meanwhile, is clearly associated with age 290 ( $16.5 \%$ of the variance).

On axis 1 (Table 8.3), the intermediate classes are differentiated primarily by 292 reading tastes and then, in descending order, by music, movies, and television tastes: 293 it seems safe to say that there is a capital composition effect here, the volume of 294 cultural capital having perhaps the strongest distinguishing effect in this central 295 region of social space - where the boundaries between graduates and non-graduates 296 and between durations in higher education are the most significant. Meanwhile, 297 axis 2 is constructed mainly by cinema, movies thus being more associated with 298 variations in sex and/or age than with variations in capital in the middle of the 299 social space. Indeed, the correlations (i.e. eta $^{2}$ ) between variables which determine 300 social position support these interpretations. The variance on axis 1 is can mainly be 301 explained by the respondent's own educational level $(17.8 \%)$, followed far behind 302 by the mother's educational level (8.6\%), the father's PCS (7.4\%) and age (5.9\%). 303 The variance of axis 2 is summarized first by age (17.2\%), then by gender $(9.4 \%) . \quad 304$

For the popular classes, they are separated, on axis 1, primarily by their 305 relationship to movies, and then by music and reading (in that order); on the axis 306 
2 , they are distinguished mainly by taste in music and, secondarily, reading (Table 307 8.3). Cinema and reading are less accessible than television and music, for rather 308 different reasons: visits to the cinema are determined by their economic cost and 309 the respondents' leisure habits; reading is determined by one's ability to 'read 310 codes'. In addition, music contributes here strongly to the axis associated with age: 311 juvenile music and ancient music could constitute a significant division within the 312 popular classes. In fact, again, the variance of the axis 1 is summarized not only 313 by the respondents' educational level, but also (indeed primarily) by age - which 314 dominates axis 2 as well. $\quad 315$

Note also that television seems the least distinguishing practice on axis 1 , and less 316 and less when passing from the bourgeois to the popular classes, as if the distinctive 317 consumption (and absence of consumption) of television only existed among those 318 most endowed with cultural capital. Following the same logic, on axis 1, it is among 319 the intermediate classes that reading contributes the most and that movies contribute 320 the least: reading practices, highly correlated to school experience, seem to have a 321 considerable distinctive influence in an area where variations in cultural capital are 322 at their strongest (it is also the case, as we have seen, among the intermediate classes 323 that education correlates most strongly with axis 1). Conversely, the relationship to 324 cinema, less framed by educational institutions and more correlated with age (and 325 gender) than with education, exhibits comparatively little variance.

Another noteworthy variation is the fact that the male/female balance of tastes 327 differs from one class to another. Gender has little structural influence among the 328 bourgeois classes (whatever the axis), but it is correlated with age on axis 2 for 329 the intermediate classes and it is also present, albeit secondarily, on the first two 330 axes for the popular classes. The popular classes are thus distinguished by a strong 331 association of gender, age and cultural capital effects (via education on axis 1 and 332 SES on axis 2) in the structuration of their tastes, while for the other classes cultural 333 capital seems to be clearly distinct from age (and gender in the intermediary classes). $\quad 334$ We will return to this discussion using other methods.

\section{The Scale of Cultural Legitimacy: A Truly Multidimensional Social Space}

\section{An Empirically Grounded Scale}

We now proceed to further analyse the homology between social space and the 339 space of tastes. Our initial approach involves an exploration of the scale of cultural 340 legitimacy. Usually, the first axis of factorial spaces of tastes is considered a 341 satisfying representation of this scale, because this axis is correlated with indicators 342 of economic and cultural capital. We will establish that this is a good proxy, but also 343 that it is worth going into detail. 
We have tested elsewhere several techniques for constructing scales of legitimacy 345 empirically (Robette and Roueff 2014). One point must be retained here. The 346 mutual ranking of tastes and social positions varies significantly according to their 347 indicators: for tastes, indicators of participation, of abstract claims, of knowledge, 348 all related to artistic genres or to individual artists or works; for social positions, 349 indicators of income, of degree, of occupational category (and sometimes of age, 350 and of racial or sexual self-identification). One of the main benefits of geometric 351 data analysis (GDA) is that it enables the combination of these various indicators 352 in order to study the structuring effects of their interactions. Rather than choosing 353 only one, or considering them as competing and ranking their specific effects, GDA 354 is able to better account for the artificiality of statistical variables: any indicator is 355 only an approximation of reality, and techniques that calculate their interactions' 356 effects offer to minimize this approximation.

\section{A “U” Shape: A Multidimensional Scale}

On the MFA of tastes, cultural and economic capitals are highly correlated with the 359 first axis, and age and sex with the second axis: the latter are of lesser weight, but 360 still important (Fig. 8.3). Besides, it has been established that cultural and economic 361 capitals are not completely independent from age and sex. One can then expect that 362 indicators of social class will not be strictly aligned with axis 1, and that indicators 363 of sex and age will not be strictly aligned with axis 2 . This presents us with a simple 364 question: which social space is the space of tastes homologous with? Is the social 365 space the space of class relations only, or do class relations interact with other 366 power relations such as those of age and sex? One way to translate this question 367 into a statistical inquiry involves looking at the exact shape of the scale of cultural 368 legitimacy, beyond the proxy of axis 1 .

All class indicators form a curve, more precisely an elongated U, or bell curve, 370 from north-east to north-west, through the south of the geometrical plane. In 371 addition, the most elongated variables according to this $U$ are those indicating 372 cultural capital. The distribution of the occupational categories (CSP) is less 373 obvious, because we used detailed categories (see legend under Fig. 8.3). Thus, 374 more typically female categories are at the top of the figure (lower-level employees, 375 personal services, mid-level social sector employees, primary school teachers, etc.); 376 more typically male categories are at the bottom (engineers, labourers, trained 377 manual workers ... ). Still, following the U, one finds workers and employees, then 378 mid-level occupations, then higher-level professionals. $\quad 379$

This observation in mind, the bell curve appears more clearly than before on 380 the space of tastes (Fig. 8.1). In the upper right (or north west?) of the figure, 381 we see the absence of participation and the most shared, established (old) and 382 female tastes. In the upper left, we find the highest degrees of participation and 383 legitimacy. The bottom of the curve (and thus the middle of the $U$ ) is neither 384 lowbrow nor highbrow, but characterised by emerging and male tastes. In summary, 385 


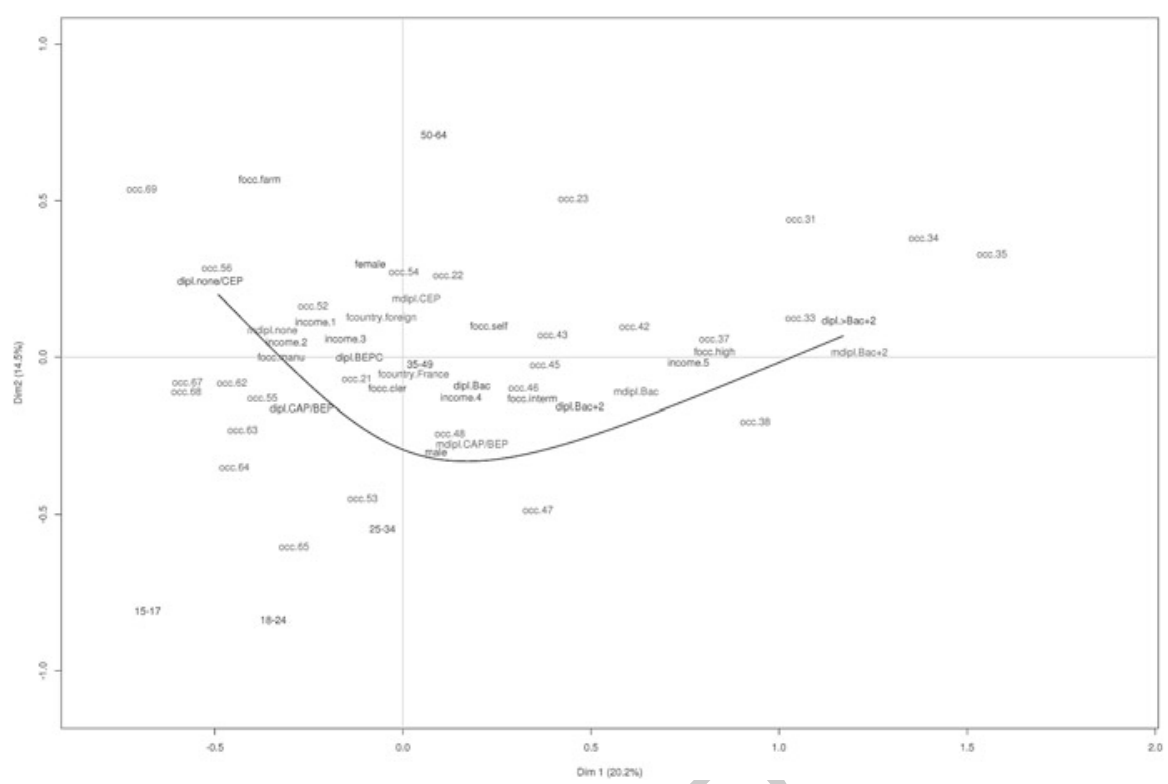

Fig. 8.3 Projection of social characteristics on the MFA of tastes

Prefix "occ" stands for interviewee's occupation, "dipl" for interviewee's diploma, "mdipl" for mother's diploma, "focc" for father's occupation, "fcountry" for father's country of origin The categories for interviewee's occupation are: $21=$ craftsman, $22=$ shopkeeper, $23=$ business owner, $31=$ professional, $33=$ public sector executive, $34=$ teacher, $35=$ information, art and show business, $37=$ administration or trade business executive, $38=$ business engineer or technical executive, $42=$ primary school teacher, $43=$ health or social service intermediate occupation, $45=$ public sector administrative intermediate occupation, $46=$ business administrative and trade intermediary, $47=$ technician, $48=$ foreman, $52=$ public sector clerk, $53=$ policeman or serviceman, $54=$ business administrative clerk, $55=$ trade clerk, $56=$ private service worker, $62=$ industry skilled worker, $63=$ craft skilled worker, $64=$ driver, $65=$ handling, storage and transport skilled worker, $67=$ industry worker, $68=$ craft worker, $69=$ farm worker

the dominant scale of cultural legitimacy, defined through the homology between 386 the distribution of capitals and the distribution of tastes, forms a bell curve 387 corresponding simultaneously to the power relations of class and to the power 388 relations of sex and age. This does not challenge the usual approximation through 389 which the scale is identified with the first axis of factorial analyses, or with the 390 simple cross-tabulation of social positions and tastes. These remain good proxies. 391 But we demonstrate here that the scale of cultural legitimacy is structured not only 392 by social positions, but also by positions of sex and age, without any linear effect 393 of the interaction of these last two variables. This point might be explored further, 394 through the study of structural effects and then the study of interactions between the 395 variables class, sex and age. 
However, a more precise and refined exploration is possible thanks to regression 398 analyses, if well used. Regression modeling and GDA are usually considered to 399 represent two opposing, incompatible statistical 'philosophies' (see introduction of 400 this volume). Adherents of the one approach might claim that regression modelling 401 is able to uncover causal relations beyond the observed correlations, while the 402 GDA is only really useful for inductive description or exploration of data. Those 403 on the other side would argue that the former method merely imitates experimental 404 sciences, their protocols for purifying the contexts of observation, and their quest for 405 the strongest causal effect, while the latter respects both the multidimensionality of 406 sociological explanations, and the inexhaustibility and historicity of social contexts. 407 However, from a statistical point of view, both sets of techniques are based on 408 the same mathematical principles: correlations between variables (for PCA and 409 linear regression) or simple cross-tabulations (for MCA and logistic regression). 410 From an epistemological point of view, both approaches face the same possibilities 411 and limitations: for instance, they may reveal correlations and hidden structures, 412 which can only be interpreted as 'clues for causality', but never as 'mathematical 413 evidence'.

We then propose a method to use regression analysis in the framework of GDA 415 in order to study structural effects. Another method already exists, enabling the 416 visualisation of the results of a regression by projecting the multidimensional space 417 constructed from the independent variables of the model, and then the dependent 418 variable as a supplementary: the global and partial effects of the independent vari- 419 ables can thus be compared (Rouanet et al. 2002). We call our method Standardized 420 Factorial Analysis (Bry et al. 2015). This name is derived from the standardization 421 methods used in demography (Léridon and Toulemon 1997; Deauvieau 2011). It is 422 able to standardize a factorial space by one or more variables whose effect is isolated 423 (i.e. controlled) through a linear regression. More precisely:

- First, we start with a traditional correspondence analysis (MCA, PCA, MFA, 425 etc.), designed to build a new data table (called C) with the coordinates of 426 the individuals on each axis of this analysis (here MCA). This results in the 427 table Individuals $\mathrm{x}$ Coordinates, with $i$ rows and $p$ columns $(i$ is the number of 428 individuals and $p$ is the number of principal components of the MCA). At this 429 stage, one can choose to retain only the first principal components, those that 430 contain the most information.

- Then, $p$ linear regressions are performed, i.e. one for each column of the previous 432 table C. The coordinates of the individuals of the MCA (i.e. the variables of C) 433 are used one after the other as the dependent variable, with (for example) sex and 434 age as independent variables.

- The residuals are retained for each of the regressions; resulting in a new table 436 (called R) with $i$ rows and $p$ columns. The quantitative variables of $\mathrm{R}$ correspond 437 to the coordinates of individuals in the initial MCA, net the sex and age structure. 438 
- A PCA is then performed on table R, which provides a new cloud of individuals, 439 i.e. a new space.

- The variables that were used to build the original MCA are then projected onto 441 this space as supplementary variables: what appears is the factorial space of 442 originally active variables, net the sex and age structure of the population. To 443 the extent that the PCA is not performed directly on the variables of the original 444 MCA, one cannot obtain the contributions of these variables. However, all other 445 tools for the interpretation of supplementary variables may be used ( $\cos ^{2}, \mathrm{v}$-test, 446 $\left.\mathrm{eta}^{2}\right)$.

For a short illustration, Figs. 8.4 and 8.5 show the space of tastes for movies 448 before and after the standardization of age and sex - knowing that the first axis, 449 correlated with the volume of capitals, reflects the intensity of practice (high at 450 left, low at right) and that the second axis, correlated with age and sex, reflects - 451 apparently - the legitimacy of tastes (Bry et al.). The surprise with the traditional 452 MCA (Fig. 8.4) is to see auteur movies in the centre of the first axis: legitimate taste 453

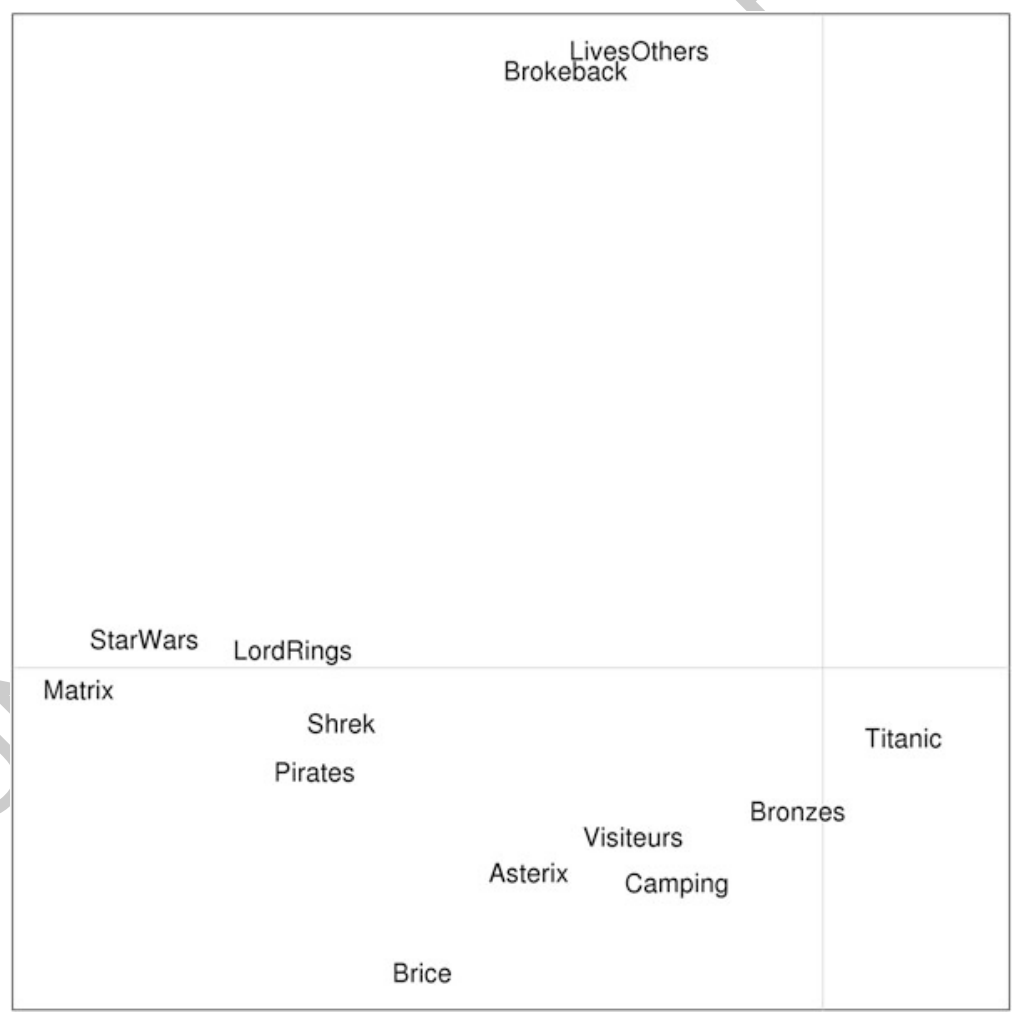

Fig. 8.4 The movies « especially liked » in the space of tastes for cinema (axes 1-2; «classical» MCA) 


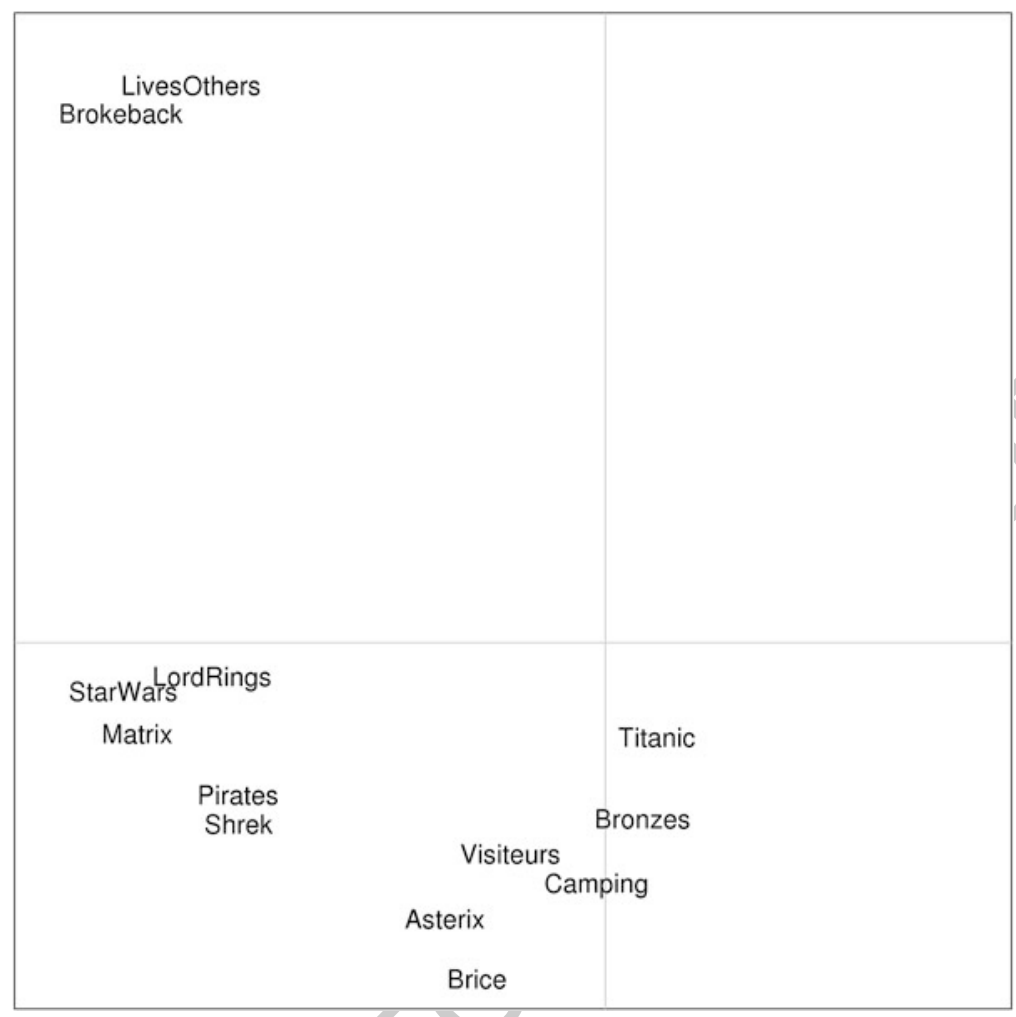

Fig. 8.5 The movies « especially liked » in the space of tastes for cinema (axes 1-2; Standardized Factor Analysis)

is related to a less intense practice than a taste for Hollywood action and science 454 fiction movies. 455

However, after performing the SFA (Fig. 8.5), the result is clear. Both figures 456 present the three same groups of relatively similar films. Now, though, the French 457 comedies have slightly moved to the right of the first axis. Moreover, the two auteur 458 movies are now at the extreme left of the graph, at the same level of intensity as 459 the action and science fiction movies. The comparison of the two spaces, one with 460 structural effects and one without, thus shows that highbrow cinéastes' practices are 461 as intense as those of action-movie lovers when sex and age are equivalent. Or, to put 462 it differently, the observed association between the taste for art films and a relatively 463 limited level of practice is the result of the sex and age structure of the population, 464 as women and older people tend to watch fewer movies in general, while at the same 465 time having more legitimate tastes.

SFA also raises a more general set of questions. The many applications we have 467 attempted all point to the same phenomenon: when structural effects are neutralized, 468 the initial multidimensional space remains almost the same in its general pattern. 469 
Some categories may move, such as auteur movies in the example shown here, 470 but the overall structure of the cloud of categories and the interpretation that 471 can be given of its different factors survive the neutralization, including when 472 controlling for several highly explanatory variables (such as social class, sex, age, 473 and educational level). This probably illustrates a more general epistemological 474 assumption: social determinisms observed through statistical variables, even when 475 well established, are probabilistic and not mechanical, and moreover they are partial 476 in the sense that they produce their effects only when associated with each other.

\section{Conclusion}

In this chapter, we have tested several hypotheses related to the social differentiation 479 of lifestyles: whether there exists a structural homology between the entirety of the 480 social and cultural spaces as wholes, by categorising four cultural domains (TV, 481 reading, cinema and music); whether the same structural homology applies at the 482 scale of the different social classes; and the extent of the associations between the 483 factors structuring lifestyles (volume and composition of capital as well as gender 484 and age).

While the results are not analysed in full detail here (although they are in other 486 papers, see Robette and Roueff 2017, 2018), we have argued for the use of unusual 487 or innovative statistical tools - such as MFA, CSA and SFA - which could open 488 new avenues for future investigations in the field of lifestyles and cultural tastes and 489 practices.

\section{References}

Bennett, T., Emmison, M., \& Frow, J. (1999). Accounting for tastes: Australian everyday cultures. 492 Cambridge: Cambridge University Press.

Bennett, T., Savage, M., Silva, E., Warde, A., Gayo-Cal, M., \& Wright, D. (2009). Culture, class, 494 distinction. London/New York: Routledge.

Borges Pereira, J. V. (2005). Classes e Culturas de Classe das Famílias Portuenses. Classes sociais 496 $e$ «modalidades de estilização da vida» na cidade do Porto. Porto: Afrontamento/Instituto de 497 Sociologia da Faculdade de Letras da Universidade do Porto.

Bourdieu, P. (1979). La distinction. Critique sociale du jugement. Paris: Minuit.

Bry, X ., Robette, N \& \& Roueff, O. (2015). A Dialogue of the deaf in the statistical theater? Adressing structural effects within a geometric data analysis framework. Quality \& Quantity, 501 50(3), 1009-1020.

Chauvel, L. (1999). Du painet des vacances: lacensommation des catégories socioprofessionnelles 503 s'homogénéise t elle (encore) ? Revue Française de Sociologie, XL(1), 79 96. 504

Deauvieau, J. (2011). Est-il possible et souhaitable de traduire sous forme de probabilités un 505 coefficient logit ? Réponse aux remarques formulées par Marion Selz à propos de mon article 506 paru dans le BMS en 2010. Bulletin de Méthodologie Sociologique, 112(1), 32-42. 507

Duval, J. (2011). L'offre et les goûts cinématographiques en France. Sociologie, 2(1), 1-18. 508 
Escofier, B., \& Pagès, J. (1990). Multiple factor analysis. Computational Statistics \& Data 509 Analysis, 18, 121-140.

Escofier, B., \& Pagès, J. (2008). Analyses factorielles simples et multiples. Objectifs, méthodes et 511 interprétation. Paris: Dunod.

Fabiani, J. L. (1995). Lire en prison. Une étude sociologique. Paris: BPI.

Grignon, C., \& Passeron, J. C. (1989). Le savant et le populaire. Misérabilisme et populisme en 514 sociologie et en littérature. Paris: Gallimard/Seuil/EHESS.

Le Roux, B., \& Rouanet, H. (2004). Geometric data analysis: From correspondence analysis to 516 structured data analysis. New York: Springer. $\quad 517$

Le Roux, B., \& Rouanet, H. (2010). Multiple correspondence analysis. Thousand Oaks: Sage. 518

Léridon, H., \& Toulemon, L. (1997). Démographie. Approche statistique et dynamique des 519 populations. Paris: Economica.

Prieur, A., Rosenlund, L., \& Skjott-Larsen, J. (2008). Cultural capital today: A case study from 521 Denmark. Poetics, 36, 45-71.

Robette, N., \& Roueff, O. (2014). An eclectic eclecticism: Methodological and theoretical issues 523 in the quantification of cultural omnivorism. Poetics, 47, 23-40. 524

Robette, N., \& Roueff, O. (2017). L'espace contemporain des goûts culturels. Homologies 525 structurales entre domaines de pratiques et entre classes sociales. Sociologie, 8(4), 369.

Robette, N., \& Roueff, O. (2018). Une légitimité multidimensionnelle. L'échelle de légitimité 527 culturelle et les interactions entre diplôme, âge et sexe. Unpublished manuscript. 528

Rosenlund, L. (2000). Cultural change in Norway: Cultural and economic dimensions. Interna- 529 tional Journal of Contemporary Sociology, 37(2), 245-275. 530

Rouanet, H., Lebaron, F., Hay, V. L., Ackermann, W., \& Le Roux, B. (2002). Régression et analyse 531 géométrique des données: réflexions et suggestions. Mathématiques et Sciences Humaines, 160, 532 $13-46$.

Saperta, G. (1990). Probabilités, analyse des données et statistique. Paris: Technip Editions. 534

Savage, M., \& Gayo, M. (2011). Unravelling the omnivore: A field analysis of contemporary 535 musical taste in the United Kingdom. Poetics, 39(5), 337-335. 


\section{AUTHOR QUERIES}

AQ1. Please confirm the chapter title.

AQ2. Please confirm the affiliation details for all the authors.

AQ3. Please provide details for "PCF (2008), Coulangeon (2003), Détrez (2011), Octobre (2011), Christin (2012), Roose et al. (2012), Glévarec and Pinet (2017), Peterson and Kern (1996)" in the reference list or delete the citation from the text if applicable.

AQ4. Please provide better quality figures for Figs. 8.1 to 8.3.

AQ5. Please confirm the presentation of all the Tables.

AQ6. References "Chauvel (1999), Saporta (1990)" were not cited anywhere in the text. Please provide in text citation or delete the reference from the reference list. 